\title{
Heteropolyacids. Versatile green catalysts usable in a variety of reaction media*
}

\author{
Makoto Misono ${ }^{1}$, Izumi Ono², Gaku Koyano², and Atsushi Aoshima ${ }^{3}$ \\ ${ }^{1}$ Department of Environmental Chemical Engineering, Kogakuin University, Nishi- \\ shinjuku, Shinjuku-ku, Tokyo 163-8677, Japan; ${ }^{2}$ Department of Applied Chemistry, \\ The University of Tokyo, Bunkyo-ku, Tokyo 113-8656, Japan; ${ }^{3}$ Asahi-Ciba Limited, \\ Minato-ku, Tokyo 105-0003, Japan
}

\begin{abstract}
Basic characteristics of heteropolyacids as green catalysts are overviewed, focusing on the various reaction fields in which the heteropolyacid catalysts function as acid and oxidation catalysts, and then two industrial processes which were made very green by the use of heteropolyacid catalysts in liquid biphase systems are described. In this context an interesting new reaction field formed at the interfacial layer of a solid heteropolyacid and liquid has also been reported.
\end{abstract}

\section{INTRODUCTION}

Chemical technology of the next century necessitates much more efficient usage of energy and resources, in order to minimize the undesirable environmental impact competing with the rapidly growing population. At the same time, the control of hazardous effects of chemical substances is indispensable for the sound development of chemical science and technology. To cope with these serious problems, the establishment of environmentally friendly products and processes has been pursued for years. Recently, extending further this concept, the green chemistry movement has emerged and is becoming a big wave $[1,2]$.

As already pointed out [1,2], both greener catalytic processes and catalytic processes for greener products must play key roles in green chemistry. In the meanwhile, as green chemistry considers the entire life cycle of product, the priority of R\&D cannot be determined unless the "greenness" of the process or product for the entire system is evaluated. This is the reason why it is necessary to establish the concept of greenness or a "green index", which is usable without much difficulty, even though this is not an easy task. To evaluate quantitatively the greenness, or the extent of reduction of undesirable environmental impact, the following items must be considered; (1) consumption of resources, (2) consumption of energy, (3) undesirable effects on human beings, (4) undesirable effects on ecosystems, and (5) safety (physical, chemical, and biological), in addition to efficiency.

If one applies the principles proposed for green chemistry [1], the items listed in Table 1 may be the R\&D targets of catalysts for green chemistry [3]. Besides, developments of green products including long-life products are necessary.

In this article, the heteropolyacid (HPA) catalysts will be introduced as promising candidates for green catalysts in the following order; an overview, latest experimental result, and then examples of industrial application. As described below, several successful examples have already demonstrated that heteropolyacids can be used as green catalysts. Furthermore, since they can be active solid acid catalysts and can provide unique reaction fields such as pseudoliquid, that is, "catalytically active solid solvent," HPA catalysts will find more green/sustainable applications in future.

*Pure Appl. Chem. Vol. 72, No. 7, 2000. A special topic issue on green chemistry. 
Table 1 Priority targets of R\&D of catalysts for green chemistry [3]

1. Stoichiometric to catalytic reactions

E.g., selective oxidation

2. Multi- to fewer step routes

3. Liquid acid and base to solid acid and base catalysts

4. Safer processes

E.g., avoidance of dangerous or toxic reagents and by-products

5. Improvements of reaction media

E.g., nonsolvent, solid-state, water, supercritical media

6. Routes of higher atom utilization or economy

\section{HETEROPOLYACID CATALYSTS}

Heteropolyacids and their salts are useful acid and oxidation catalysts for various reactions and there are already many practical applications. There are several advantages from using the HPA catalysts [46]. One of the most interesting aspects may be the fact that they can be used in various kinds of reaction media or fields.

In the case of solid catalysts for gas-phase reactions, there are three very different classes of catalysis; (a) ordinary surface-type, (b) "pseudoliquid" (bulk-I) type and (c) bulk-II type [4,5]. Pseudoliquid behavior is observed for some heteropolyacids in the solid state. Because of the flexible lattice (variable secondary structure), reactant molecules are absorbed into the three-dimensional solid bulk and react there. In other words, the reaction field of the solid catalyst becomes three-dimensional like reactions in solution (catalytically active solid solvent). Owing to this behavior, HPA catalysts often exhibit very high catalytic activities and unique selectivities. A remarkable example of the surface-type catalysis is observed for highly porous acidic cesium salts, (e.g., $\mathrm{Cs}_{2.5} \mathrm{H}_{0.5} \mathrm{PW}_{12} \mathrm{O}_{40}$ ), which are much more active for several reactions than zeolites and sulfated $\mathrm{ZrO}_{2}$. Even shape-selective catalysis can evolve in this case by control of the porosity. As for catalysis in the liquid phase, a greater variety of catalysis types is present [7]. HPAs can act as solid catalysts showing (d) ordinary surface-type catalysis, as well as (e) catalysis in pseudoliquid, and as soluble catalysts in (f) single homogeneous phase and (g) biphase (phase-transfer) systems. It sometimes happens that, (h) even though the catalyst exists mostly in the solid state, a small portion which is dissolved in solvent mainly catalyzes reactions. These different types of catalysis are schematically illustrated in Fig. 1.

Another unique reaction field was recently found [8], where protons in the surface layer of acidic cesium salts of $\mathrm{H}_{3} \mathrm{PW}_{12} \mathrm{O}_{40}$ were much more active than protons in homogeneous solution.

The reaction is hydrolysis of bistrimethylol propane monoformal (eq. 1, BTMP to TMP) in water at $348 \mathrm{~K}$. Catalysts used (usually $0.1-0.15 \mathrm{~g}$ ) were heteropolyacids $\left[\mathrm{H}_{3} \mathrm{PW}_{12} \mathrm{O}_{40}(\mathrm{HPW}), \mathrm{H}_{4} \mathrm{SiW}_{12} \mathrm{O}_{40}\right.$ ( $\mathrm{HSiW}), \mathrm{H}_{4} \mathrm{GeW}_{12} \mathrm{O}_{40}(\mathrm{HGeW})$, and $\left.\mathrm{H}_{3} \mathrm{PMo}_{12} \mathrm{O}_{40}(\mathrm{HPMo})\right]$ and their acidic Cs salts that were prepared as previously reported [9]. Prior to the reaction, the catalysts were treated at $523 \mathrm{~K}$ in an $\mathrm{N}_{2}$ flow for 2 h. Amberlyst 15 (A-15, pretreated in $\mathrm{N}_{2}$ flow at $373 \mathrm{~K}$ ), $\mathrm{H}_{2} \mathrm{SO}_{4}$, and $\mathrm{HCl}$ were tested for comparison. Products were analyzed by gas chromatography.

Catalytic activities can be compared by the data in Table 2. $\mathrm{Cs}_{2.5} \mathrm{H}_{0.5} \mathrm{PW}_{12} \mathrm{O}_{40}(\mathrm{Cs} 2.5 \mathrm{PW})$ was the most active per proton in the solution or in the bulk of solid catalyst, and $\mathrm{Cs}_{2.2} \mathrm{H}_{0.8} \mathrm{PW}_{12} \mathrm{O}_{40}(\mathrm{Cs} 2.2 \mathrm{PW})$

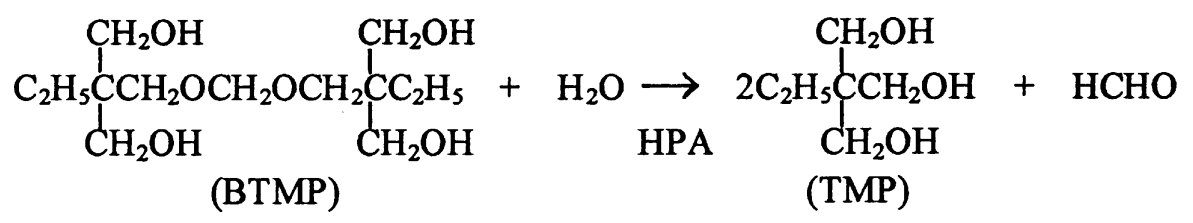




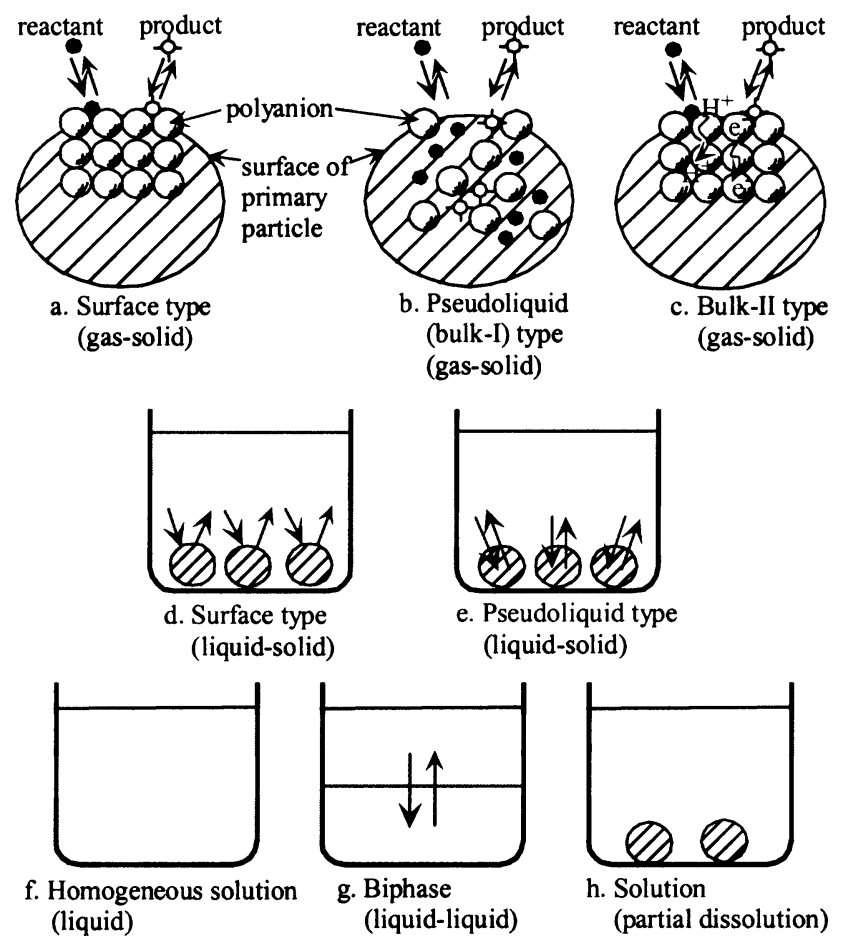

Fig. 1 Various types of catalysis of heteropolyacids (schematic).

was the most active when nominally compared per surface proton and per weight of catalyst. Dissolved acids showed the activity order of $\mathrm{HPW}>\mathrm{HSiW}>\mathrm{HGeW}>\mathrm{HPMo}>>\mathrm{H}_{2} \mathrm{SO}_{4}, \mathrm{HCl}$. Since the protons on the surface are only a part of the total protons in the solid bulk, Cs2.2PW and Cs2.5PW have much higher turnover numbers than dissolved acids.

The remarkable feature of this system may be seen, for example, in Fig. 2, where the time courses of the reaction are illustrated. When Cs3PW, which was almost inactive, was added to the reaction solution containing HPW, the reaction rate instantaneously jumped up 5-6 times (case 1). The addition of HPW to the system containing Cs3PW similarly enhanced very much the catalytic activity (case 2). It is interesting to note that a similar phenomenon was also observed for the combination of Cs3PW and

Table 2 Catalytic activities for hydrolysis of formal (eq. 1).

\begin{tabular}{lcc}
\hline Catalyst & mol proton ${ }^{-1} \mathrm{~h}^{-1}$ & $\begin{array}{l}\text { Reaction rate } \\
\mathrm{mmol} \mathrm{g}^{-1} \mathrm{~h}^{-1}\end{array}$ \\
\hline $\mathrm{Cs} 2.5 \mathrm{PW}$ & $25.6(59.3)$ & 4.00 \\
$\mathrm{Cs} 2.2 \mathrm{PW}$ & $25.4(107)$ & 6.40 \\
$\mathrm{HPW}$ & 3.98 & 4.15 \\
$\mathrm{Cs} 2.5 \mathrm{SiW}$ & 4.60 & 2.15 \\
$\mathrm{HSiW}$ & 3.18 & 4.42 \\
$\mathrm{~A}-15$ & 0.92 & 5.01 \\
$\mathrm{H}_{2} \mathrm{SO}_{4}$ & 1.77 & \\
$\mathrm{HCl}$ & $0.85-1.86$ & \\
\hline
\end{tabular}

Figures in parentheses are the rates per surface proton (nominally calculated assuming uniform composition and insolubility).

(C) 2000 IUPAC, Pure and Applied Chemistry 72, 1305-1311 


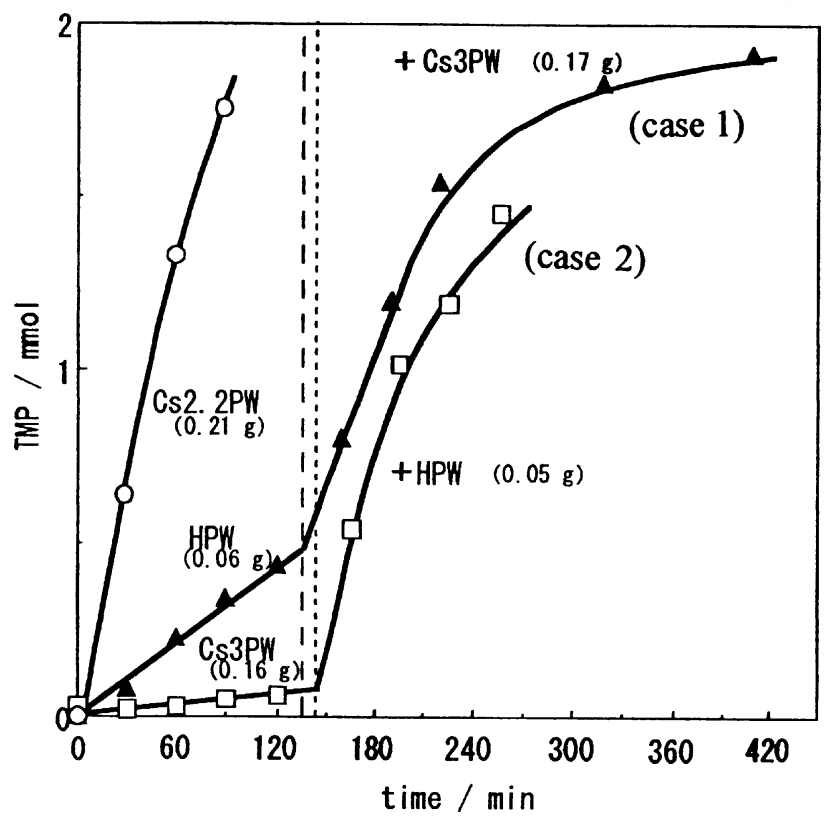

Fig. 2 Time courses of hydrolysis of bistrimethylol propane monoformal (eq. 1). $\bigcirc$ : Cs2.2PW (0.21 g); $\mathbf{\Delta}$ : HPW (0.06 g) [Cs3PW (0.17 g) was added at $130 \mathrm{~min}$ (broken vertical line)]. $\square$ : Cs3PW (0.16 g) [HPW (0.05 g) was added at $136 \mathrm{~min}$ (dotted vertical line)]. Temperature; $348 \mathrm{~K}$. Solvent; water $(40 \mathrm{~mL})$. 1,4-Dioxane $(0.5$ $\mathrm{mL}$ ) was added as an internal standard.

$\mathrm{H}_{2} \mathrm{SO}_{4}$. The $\mathrm{pH}$ of the solution increased after the addition of Cs3PW (case 1) (decrease in proton concentration). UV spectra of the liquid phase of the HPW+Cs3PW system measured after the separation of the solid showed that the concentration of heteropolyanion in the solution also decreased by the addition of Cs3PW. The reaction rate tested in this liquid was very low (as low as the case of HPW of the same concentration). In contrast, the separated solid was very active. Furthermore, it was confirmed by atomic absorption spectrometry that the concentration of Cs dissolved in the solution was very low. All of these results indicate that a catalytically very active phase was formed on the surface or in the surface layer of Cs3PW by the adsorption (absorption) of polyanion and proton.

When the content of $\mathrm{Cs}$, $\mathrm{x}$ in $\mathrm{Cs}_{\mathrm{x}} \mathrm{H}_{3-\mathrm{x}} \mathrm{PW}_{12} \mathrm{O}_{40}(\mathrm{CsXPW})$, was varied, the highest activity per weight was observed for $\mathrm{C} 2.2 \mathrm{PW}$, the order being $\mathrm{HPW}<\mathrm{Cs} 1 \mathrm{PW}<\mathrm{Cs} 2 \mathrm{PW}<\mathrm{Cs} 2.2 \mathrm{PW}>\mathrm{Cs} 2.5 \mathrm{PW}>>\mathrm{Cs} 3 \mathrm{PW}$ $=0$. This is very different from the typical surface-type catalysis for which Cs $2.5 \mathrm{PW}$ was always most active and the activity of Cs1PW and Cs2PW were very low [4,5]. The reaction proceeded at a much lower rate in solution if normalized to the number of protons accessible to the reactant. As for the solubility of these salts, HPW was totally soluble, Cs $2.2 \mathrm{PW}$ partially soluble, and $\mathrm{Cs} 2.5 \mathrm{PW}$ was hardly soluble, the solubility decreasing with the Cs content. Therefore, the present reaction system is neither of typical surface-type or the simple sum of the surface-type and solution catalysis. The catalytic systems, Cs2.2PW and HPW+Cs3PW, may belong to a new mutant of pseudoliquid catalysis, and Cs2.5PW is an insoluble solid acid catalyst active in aqueous solution.

Anyway, it may be obvious that HPA catalysts exhibit excellent performance in a variety of reaction fields and are promising candidates as green catalysts.

\section{SUCCESSFUL INDUSTRIAL APPLICATIONS OF HPA CATALYSTS AND THEIR GREENNESS}

There are already several large-scale industrial processes utilizing HPA catalysts [4,5,11]. Here, two examples are chosen, and the characteristic feature of the processes and their greenness will be described. 
Both examples demonstrate that heteropolyacid catalysts can realize very efficient and green synthetic processes not only as solid catalysts but also as soluble biphase catalysts.

\section{Hydration of isobutylene}

This process supplies the starting material [t-butyl alcohol (TBA) or the mixture of isobutylene and water] for the two-step oxidation of isobutylene to methacrylic acid, by separating selectively isobutylene from BB spent (BBS) of naphtha cracking, comprising isobutylene, ca. 50\%, and 1- and 2-butenes, ca. $50 \%$. The 1- and 2-butenes left after reaction (BBSS) are utilized as raw materials, for example, for linear low density polyethylene (LLDPE).

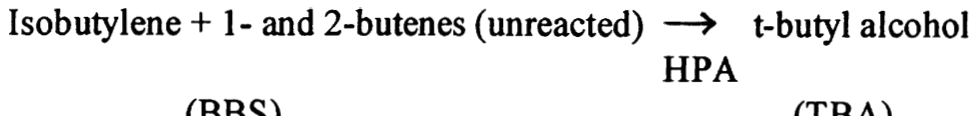

(BBS)

The excellent activity and selectivity of HPA catalysts are obtained when their concentrations are above $50 \mathrm{wt} \%$. The high activity is due to the strong acidity, increased solubility of butenes, and the formation of a complex with carbocation intermediate. The high selectivity is believed to be due to the preferential coordination of heteropolyanion with isobutylene [10,11]. The established process compares very favorably with competing processes that use sulfuric acid and ion-exchange resin for catalysts.

\section{Outline of the process}

The flow diagram of the process which was commercialized by Asahi Chemical Co. is illustrated in Fig. 3. A pressurized mixture of butenes is counter-currently contacted with $50 \mathrm{wt} \%$ or more concentrated aqueous solution of heteropolymolybdate below $353 \mathrm{~K}$ to form TBA at $90-100 \%$ yield. The reaction of 1 - and 2-butenes is very low. Of the biphasic liquid in the reactor, TBA is mainly present in the aqueous catalyst solution which is simply separated in a decanter, and after removing a small amount of butenes it is distillated under reduced pressure. TBA is obtained from the top of the distillation column, and the bottom is directly recycled to the reactor. The product TBA contains about $15 \mathrm{wt} \%$ water but can directly be supplied to the subsequent oxidation process which requires steam in the feed.

\section{Efficiency and greenness of the process}

The HPA process is a one-step simple process. Water, butenes, and catalyst are the only components used. The former two are the reactants, and the catalyst which is not corrosive is directly recycled after simple separation. It is remarkable that the life of HPA catalyst is over ten years. The investment of the plant was about one half and the utility was about $60 \%$ of the sulfuric acid process. The sulfuric acid process requires extraction and decomposition of the sulfuric ester, and, moreover, sulfuric acid is very corrosive. The ion-exchange resin process needs a water-acetic acid mixture for solvent to improve the contact of reactant with catalyst, so that the problem of corrosion caused by acetic acid may be inevitable, and the hydrolysis of butyl acetate, an unavoidable co-product, is necessary.

As for the by-products, the HPA process is very selective; the oligomer of isobutylene is less than $0.1 \%$ and the conversion of n-butene less than $0.05 \%$. These values are compared with those for the sulfuric acid process, where they are $4-8 \%$ and $0.4-0.8 \%$, respectively. Hence, the latter requires tedious treatment of wastes. Thus, due to the high selectivity, easy separation, and the usage of only reactants and catalyst, the HPA process is a clean, closed (no waste), noncorrosive, energy- and resource-saving, compact system, which may be called a very green process. 


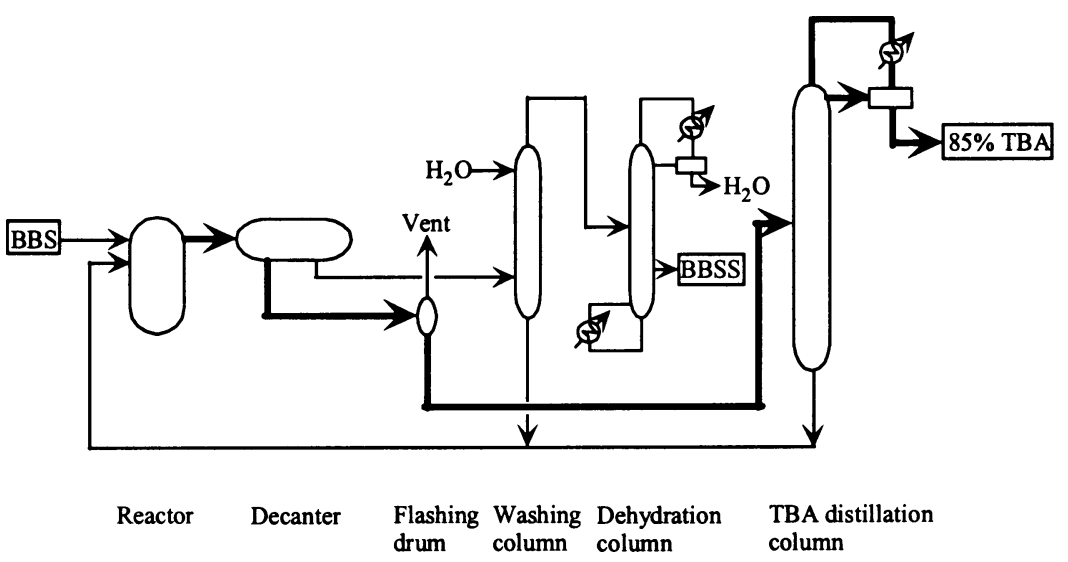

Fig. 3 Flow diagram of process for selective hydration of a mixture of isobutylene, 1- and 2-butene (Asahi Chemical Co.).

\section{Polymerization of tetrahydrofuran}

This is a ring-opening polymerization process for the conversion of tetrahydrofuran (THF) to polyoxytetramethyleneglycol (PTMG). PTMG is used as an elastic fiber and elastomer. The reaction proceeds very efficiently and selectively (narrower molecular weight distribution) also in a biphase liquid system (THF and catalyst phases). Under a certain range of the molar ratio of THF, water, and HPA, the reaction proceeds in a biphasic system, making the catalytic activity and molecular weight of PTMG appropriate. The phase-transfer mechanism of the reaction has been discussed previously [12]. PTMG is recovered from the THF phase, and the catalyst phase is used repeatedly. It was presumed that the appropriate solubility of the product polymer in the THF phase controls the molecular weight and makes the molecular weight distribution narrower [12].

The flow diagram of the process industrialized also by Asahi Chemical Co. is essentially the same as that for the TBA process shown in Fig. 3, but is still simpler. The reaction is a real catalytic one, and the separation step is very simple. The catalyst, unreacted THF which contains water, and a small amount of by-product (i.e., THF oligomer), can be recycled to the reactor without any purification, because they are the components of the reaction system. Thus, the HPA process is a simple closed system without producing waste. These are in contrast with preceding processes which utilize for catalysts super acids like fluorosulfuric acid or the combination of acetic acid and $\mathrm{HClO}_{4}$. In the latter processes the catalysts are not all reused, and waste treatments as well as further treatment of the product are necessary. The investment of the plant and the cost of utility of the HPA process were estimated to be less than one half of the preceding processes.

This is another good example of a green process using HPA as a soluble acid catalyst.

\section{REFERENCES}

1. P. T. Anastas and J. C. Warner. Green Chemistry; Theory and Practice, Oxford Univ. Press (1998).

2. J. H. Clark. Green Chem. 1, 1 (1999).

3. M. Misono. 76th National Meeting of Chem. Soc. Japan, March, 1999.

4. M. Misono. Catal. Rev. Sci.-Eng. 29, 269 (1987); 30, 339 (1987).

5. T. Okuhara, N. Mizuno, M. Misono. Adv. Catal. 41, 113 (1996); N. Mizuno and M. Misono. Chem. Rev. 98, 199 (1998).

6. I. V. Kozhevnikov. Chem. Rev. 98, 171 (1998). 
7. G. Koyano, K. Ueno, M. Misono. Appl. Catal. A. General 181, 267 (1999).

8. I. Ono, G. Koyano, M. Misono. 82nd National Conference on Catalysis, Matsuyama, 1998; M. Misono. Kikan Kagaku Sosetu. 41, 25 (1999).

9. S. Tatematsu, T. Hibi, T. Okuhara, M. Misono. Chem. Lett. 865 (1984); T. Okuhara, T. Nishimura, M. Misono. Stud. Surf. Sci. Catal. 101, 581 (1996).

10. A. Aoshima. Shokubai 29, 378, (1987); A. Aoshima, S. Yamamatsu, T. Yamaguchi. Nippon Kagaku Kaishi 233 (1990).

11. M. Misono and N. Nojiri. Appl. Catal. 64, 1 (1990).

12. A. Aoshima, S. Tonomura, S. Yamamatsu. Polym. Adv. Technol. 2, 127 (1990).

\section{AFTERWORD}

\section{Status of the field of the authors with respect to Green Chemistry}

Professor Makoto Misono is now the chairman of the two committees of the Chemical Society of Japan for Environment and Safety, and for Green Chemistry. Ms. Ono and Dr. Koyano were the Prof. Misono's coworkers. Dr. Atsushi Aoshima was the principal inventor at Asahi Chemical Co. of the two industrial processes which are introduced in this article, and is now the president of Asahi-Ciba Limited.

\section{The status of green chemistry in Japan}

In Japan, there are several activities for green chemistry, such as those of the Chemical Society and other academic societies, and of national institutions. Japan Chemical Industry Association (JCIA) is also implementing various programs to study and minimize the environment impacts of chemical substances, including Responsible Care. In the past, Japanese chemical industry has been one of the most active in the efforts for the developments of environmentally friendly processes as well as of chemical technologies for environmental protection such as DeNOx, DeSOx of flue gases from power plants and control of automobile emissions. Now Japan Chemical Innovation Institute (JCII) is going to play a leading role in the green chemistry movement in Japan. It organized an intensive workshop on green chemistry in 1999, after a long discussion and in collaboration with several academic, governmental, and industrial sectors. An organization for green/sustainable chemistry, which is expected to be a center of green chemistry in Japan and named Green and Sustainable Chemistry Network in Japan (GSC Network, Japan) was launched in March 2000.

(C) 2000 IUPAC, Pure and Applied Chemistry 72, 1305-1311 